This is a self-archived - parallel published version of this article in the publication archive of the University of Vaasa. It might differ from the original.

\title{
How culture shapes user responses to firm- generated content on social media : the role of cultural dimensions of in-group collectivism, indulgence, and masculinity
}

Author(s): Chwialkowska, Agnieszka; Kontkanen, Minnie

Title: How culture shapes user responses to firm-generated content on social media : the role of cultural dimensions of in-group collectivism, indulgence, and masculinity

Year: $\quad 2017$

Version: Accepted manuscript

Copyright $\quad$ C) 2017 Inderscience Publishers

Please cite the original version:

Chwialkowska, A., \& Kontkanen, M., (2017). How culture shapes user responses to firm-generated content on social media : the role of cultural dimensions of in-group collectivism, indulgence, and masculinity. International journal of export marketing 1(4), 328-356.

http://dx.doi.org/10.1504/IJEXPORTM.2017.10011495 


\section{Agnieszka Chwialkowska*}

Department of Marketing and Real Estate,

Richards College of Business,

University of West Georgia,

1601 Maple St., Carrollton, GA 30118, USA

Email: achwialk@westga.edu

${ }^{*}$ Corresponding author

\section{Minnie Kontkanen}

Department of Marketing

University of Vaasa,

Wolffintie 34, 65200 Vaasa, Finland

Email: minnie.kontkanen@uva.fi 


\title{
How culture shapes user responses to firm-generated content on social media: the role of cultural dimensions of In-group Collectivism, Indulgence, and Masculinity
}

\author{
Abstract \\ As users across the globe interact with firms on social media, firms operating in international \\ markets are striving to generate desired responses to their social media content in culturally \\ diverse markets. The objective of this study is to establish how user responses to firm-generated \\ content on social media are affected by three cultural dimensions: in-group collectivism, \\ indulgence, and masculinity. To accomplish this objective, we conduct an exploratory inquiry \\ involving research diaries, open-ended narratives, and interviews with informants from Finland \\ and Poland. Our study reveals that it is not the intensity of social media use that differs among \\ cultures with different levels of in-group collectivism, as previously thought, but whether user \\ responses to firm-generated content are public (content sharing, commenting, or clicking 'like', \\ or private (reading and watching content). We establish how previously neglected cultural \\ dimensions of masculinity vs. femininity and indulgence vs. restraint shape user responses to \\ firm-generated content. Moreover, we demonstrate that cultural dimensions should not be \\ studied in isolation. The study offers critical managerial insights regarding how to appeal to \\ motivations of social media users from different cultural backgrounds. \\ Keywords social media, responses to firm-generated content, in-group collectivism, \\ individualism, indulgence vs. restraint, masculinity vs. femininity, social norms, Hofstede \\ cultural dimensions, GLOBE cultural dimensions
}




\section{Introduction}

With 2.05 billion Facebook users globally (Statista 2017), an astounding 2.5 billion comments are posted daily on over 50 million company pages on this social media platform (Forbes 2015). As social media has become an integral part of our daily lives, firms try to be a part of user experiences. Firm-generated content that is well integrated into user social media activities succeeds in generating desired user responses such as clicks 'share'. It also strengthens brand trust and attitudes, and leads to increased customer profitability (Kumar, Bezawada, Rishika, Janakiraman \& Kannan 2016; Mosteller and Poddar 2017; Phua and Anh 2017). However, the majority of firm-generated content does not result in desired user responses, and often leaves users with a feeling that firm-generated content interrupts their social media activity (AdReaction, 2010, Nelson-Field \& Taylor 2012).

As called for by Sloane (2015), Stone (2010), Stephen, Sciandra, and Inman (2015), to help firms create content that will be better integrated into user social media activities and, consequently, result in desired user responses, we need to first understand what motivates users to respond to social media content (Pagani, Hofacker, \& Goldsmith, 2011; Van Doorn, Lemon, Mittal, Nass, Pick, Pirner, \& Verhoef, 2010). Despite increasing research focusing on online user motivations (Muntinga et al. 2011; Saridakis, Baltas, Oghazi \& Hultman 2016), there is still no consensus as to what motivates different user responses. This lack of consensus regarding user motivation might stem from ignoring the cultural background of the subjects studied. Social media usage is influenced by enabling technologies, governmental policies and socio-cultural factors (Berthon, Pitt, Plangger, \& Shapiro 2012). While the former two tend to be similar across the developed world, the latter still influence our online behaviours (Goodrich and de Mooij 2014; Okazaki and Taylor 2013; Park et al. 2015). However, the question on how culture shapes responses to firm- 
generated content on social media remains unanswered (Dahl, 2015; Goodrich and De Mooiji 2014; Okazaki and Taylor 2013).

While existing studies increase our understanding of the differences in online behaviour across countries, the majority of these studies are descriptive and narrowed to conducting cross-national comparisons (e.g., Chapman and Lahav 2008; Choi, Hwang \& McMillan 2008; Shin 2010). A few that demonstrate how behavioural differences can be explained by cultural dimensions arrive at contradictory findings (Goodrich and De Mooiji 2014; Okazaki and Taylor 2013; Pornpitakpan 2004; Yang, Morris, Teevan, Adamic \& Ackerman 2011), and are too limited to fully explain the differences in user responses to firm-generated content. Their conflicting results point to several problems within the existing literature. Firstly, contradictory findings regarding the role of collectivism and power distance might be the result of analysing these cultural dimensions in isolation, whereas taking into account the joint effect of different cultural values would provide a more holistic perspective on the phenomenon. Second, existing studies consider a limited number of cultural dimensions and ignore, for instance, Hofstede’s (2010) masculinity or indulgence vs. restraint. Third, existing cross-cultural studies focus on word of mouth, opinion seeking, and social media use (Chapman and Lahav 2008; Goodrich and De Mooij 2014: Pornpitakpan 2004; Qiu et al. 2013; Yang et al. 2011), but from both theoretical and managerial perspectives, they neglect an important, area of user responses to firm-generated content. Therefore, the area of sociocultural differences on social media remains largely under-researched (Dahl, 2015; Okazaki and Taylor 2013), with calls for more studies on social media from a crosscultural perspective (Dahl, 2015; Goodrich and De Mooiji 2014; Okazaki and Taylor 2013). To address the outlined research gaps, the purpose of this study is to provide a more holistic perspective on the role of culture in shaping user responses to firm-generated content. We 
theorize the role of in-group collectivism (House, Hanges, Javidan, Dorfman \& Gupta 2004), indulgence vs. restraint, and masculinity vs. femininity (Hofstede, Hofstede \& Minkov 2010) in shaping user responses to firm-generated content. The empirical investigation focuses mainly on, although its implications are not limited to, firm-generated content on Facebook. We adopted a modified Kumar et al. (2016) definition, and defined firm-generated content on Facebook as firm-initiated marketing communication in the form of Facebook posts including text, image, or video, posted by firms on their Facebook page. Subjects from two countries with different scores on cultural dimensions were analysed: Finland and Poland. As the study aims at developing a theory, the research procedure was designed to capture users' thoughts and their immediate responses to firm-generated content and, thus, was based on research diaries, interviews, and open-ended narratives in which respondents provided an account of their experiences with social media.

As the relevant research area of user responses to firm-generated content in social media has been largely neglected in the cross-cultural literature, we answer the calls of Dahl (2015), Okazaki and Taylor (2013), and Goodrich and De Mooiji (2014). As a key contribution, we identify the differences in user responses to firm-generated content, stemming from a cultural context. By linking different responses (private vs. public) to cultural dimensions of Hofstede et al. (2010) and House et al. (2004), we demystify the previously held view (e.g. Okazaki and Taylor 2013; Goodrich and De Mooiji 2014) that individualistic and collectivistic cultures differ in the intensity of social media participation. We show that it is the response type (private vs. public), rather than intensity of social media participation that varies in individualistic and collectivistic cultures. Specifically, our contribution lies in theorizing how cultural dimensions of in-group collectivism (House et al. 2004), indulgence vs. restraint, and masculinity vs. femininity 
(Hofstede et al. 2010) explain differences in user responses to firm-generated content. Furthermore, we reveal the importance of previously neglected cultural dimensions of masculinity and indulgence vs. restraint and discover the joint effect of cultural dimensions of ingroup collectivism and masculinity. By studying subjects' immediate responses to firmgenerated content in the everyday context of online interactions that occur in their daily lives, we reveal how culture influences the importance of social norms for user responses to firmgenerated content. Moreover, before marketing professionals in international firms can generate desired user responses to firm-generated content, they need to know how user motivations differ across cultures. Thus, the paper provides guidance for international firms trying to develop their firm-generated content based on users’ cultural background.

The structure of this paper is as follows. First, we discuss the existing literature and introduce the cultural dimensions considered in this study. Second, we elaborate on our research methods and sampling choices, as well as walking the reader through our data analysis process. We then move to describe the study findings. Then, we discuss those findings and conclude with a discussion of research contributions.

\section{Literature review}

\subsection{Online behaviors and their underlying motivations}

Previous studies identified three types of online behaviours, i.e., consuming, contributing and creating (Muntinga et al. 2011; Makri \& Schlegelmilch 2017; Schivinski, Christodoulides \& Dabrowski 2016; Tsai \& Men 2017). These behaviours can be classified into two types: (1) public responses that occur when users express their opinions, publicly, by actively contributing and creating content through commenting, sharing, or clicking 'like'; or (2) private responses when users only passively consume the content, i.e., watch or read content (Muntinga et al. 2011; Makri 
\& Schlegelmilch 2017; Schivinski, Christodoulides \& Dabrowski 2016). Even though the researchers' attention has recently shifted to understanding successful firm-generated content, the focus has mainly been on content design and characteristics (Steinmann, Mau, \& Schramm-Klein, 2015; De Vries, Gensler, \&; Leeflang 2012; Lee, Hosanagar, \& Nair, 2016), rather than on how this content is integrated into users' social media activities and their motivations, which is the focus of this study.

While previous studies in a cross-cultural context open a discussion on how users across countries differ in their online behaviours, they concentrate on a limited number of online behaviours. They recognize differences in motivations for a limited range of online behaviours including social media participation, information seeking (consuming content), or word of mouth (Chapman and Lahav 2008; Goodrich and De Mooij 2014; Pornpitakpan 2004; Qiu et al. 2013; Yang et al. 2011; Yadav and Pavlou (2014), but mostly neglect the different responses to firm-generated content. As sharing, commenting, or clicking 'like' under the firm-generated content means interacting with one's Facebook friends, it is important to recognize that motivations for public and private responses to firm-generated content may differ. Knowing the differences in motivations will help firms develop firm-generated content that addresses user motives depending on a desired response outcome. Thus, this study distinguishes itself by looking at both public and private responses to firm-generated content and differentiating between motives for those two responses.

Previous studies identified several user motivations for online participation such as (1) entertainment (enjoyment, relaxation and a pastime), (2) social integration (interactions with friends, social identity, and helping), (3) personal identity (self-presentation, self-expression and self-assurance), (4) information (surveillance, knowledge, pre-purchase and inspiration), (5) remuneration (gaining reward), and (6) empowerment (exerting influence or power on others) 
(Muntinga et al. 2011; Saridakis et al. 2016). Identification of user motivations was followed by attempts to link user motivations to user responses to content in social media (Muntinga et al. 2011; Saridakis et al. 2016; de Vries, Peluso, Romani, Leeflang \& Marcati 2017). However, researchers have not arrived at a consensus regarding the relationships between response type and user motives. Firstly, these contradictory results may stem from the fact that often no distinction was made between the content type (firm-generated vs. user-generated). Secondly, no distinction was made based on the cultural background of the respondents despite prior crosscultural studies indicating that, indeed, online user motivations differ (Jiacheng, Lu, \& Francesco 2010; Goodrich and De Mooij 2014; Qiu, Lin, \& Leung 2013; Vasalou, Joinson, \& Courvoisier 2010; Yang et al. 2011). Therefore, in what follows we review the most relevant cross-cultural studies focusing on user online behaviours and their underlying motivations.

\subsection{Cross-cultural perspective}

Culture affects our cognition, attitudes, motives, and behaviours (Markus \& Kitayama 1991; Nisbett, Peng, Choi, \& Norenzayan 2001; Okazaki \& Mueller 2007; Taras et al. 2010; Shavitt, Lee, \& Johnson 2008). In the context of marketing, it is an established determinant of advertising appeals, consumer motives, and purchasing behaviours (Shavitt, Lee, \& Johnson 2008). By publicly responding to firm-generated content (e.g. sharing, commenting, or clicking 'like’), users indirectly interact with their friends on Facebook. Therefore, social norms can stimulate or inhibit public responses to content (Dholakia et al. 2004). Social norms and shared community practices are a reflection of culture, which can be defined as a set of norms to which individuals in society should adhere to (Leung et al. 2005; Rokeach 1973). Therefore, culture constitutes a form of social influence on a macro scale (Geertz 1973; Hofstede 2001). This influence is reflected in the greater popularity of local social media platforms conforming to cultural values, 
than global, more-standardized platforms. Moreover, online behaviours differ across cultures with regard to time spent using social media, the frequency of use, number of interaction partners, the nature of the relationships, topics that are discussed or published, online question asking and answering, content sharing, and online word of mouth (Christodoulides, Michaelidou, \& Argyriou 2012; Goodrich and De Mooij 2014; Pornpitakpan 2004; Qiu et al. 2013; Yang et al. 2011). In what follows, we take a closer look at the existing literature in this research area. Firstly, research in the field of online user behaviour is narrowed to conducting cross-national comparisons (e.g. Choi, Hwang, \& McMillan 2008; Muk, Chung, \& Kim 2014; Vasalou, Joinson, \& Courvoister 2010; Shin 2010; Park et al. 2015). While user motivations differ across cultures, only a limited number of studies investigated this issue. As recognized by Vasalou et al. (2010), users in the USA, UK, France, Italy and Greece are driven by different motives to participate on Facebook, or to interact with other users, and Muk, Chung, \& Kim (2013) established similar differences between users in Korea and the USA in the context of joining brand pages on social media. Moreover, users in Korea and the USA differ in their intensity of social media use (Park et al. 2015), and motivations for social media use (Choi, Hwang, \& McMillan 2008). However, while those cross-national studies provide us with valuable insights into how online behaviour varies across borders, they do not answer the question 'why' those differences occur.

Secondly, a limited number of studies that take into account cultural dimensions focus mainly on Hofstede (2010) cultural dimensions of (1) Uncertainty Avoidance (e.g. Chapman \& Lahav 2008; Markus \& Krishnamurthi 2009; Pornpitakpan 2004; Goodrich \& De Mooij 2014), (2) Power Distance (e.g. Markus \& Krishnamurthi 2009; Pornpitakpan 2004; Cho \& Cheon 2005; Goodrich \& De Mooij 2014), (3) Individualism (e.g. Cho \& Cheon 2005; Goodrich \& De Mooij 
2014; Okazaki \& Taylor 2013), and (4) Long-term Orientation (Goodrich \& de Mooij 2014; Pornpitakpan 2004).

While researchers arrived at unanimous conclusions of the influence of cultural dimensions of uncertainty avoidance and long-term orientation, studies focusing on the cultural dimension of individualism did not reach consensus (e.g. Goodrich \& de Mooij 2014; Okazaki and Taylor 2013; Yang et al. 2011). It is established that users in high uncertainty avoidance cultures take more steps to secure their privacy by keeping their public profiles on social networking sites anonymous, in comparison to low uncertainty avoidance societies (Cho 2010; Markus \& Krishnamurthi 2009). This desire to remain anonymous translates into limited content sharing and word of mouth (Chapman \& Lahav 2008). In long-term oriented cultures, anonymityseeking individuals are more passive online than users from short-term oriented cultures, where people present themselves in a self-enhancing way and are more interactive (Goodrich \& de Mooij 2014). There is, however, no agreement on the role of the individualism dimension in shaping online behaviour. Goodrich and De Mooij (2014) suggest that social media is used more in cultures with low levels of individualism. In contrast, Okazaki and Taylor (2013) argue that engagement on social media is attributed to countries with high levels of individualism, and according to Yang et al. (2011), there are no differences in the intensity of social media use across cultures with varying levels of individualism.

The inconclusive findings may indicate that it is not the intensity of the behaviour on social media that varies across cultures, but the types of responses to firm-generated content and the underlying motives. While in many online communities users share similar interests (McKenna, Green, \& Gleason, 2002; Steinman et al., 2015; Stokburger-Sauer \& Wiertz 2015), on Facebook, 
users follow a wide variety of firm-generated content regardless of the interests of their friends (Sibai, de Valck, Farrell, \& Rudd 2015). However, their public responses to firm-generated content are visible to their online friends, and some cultural dimensions will limit and others encourage their willingness to publicly respond to firm-generated content. For instance, Hofstede's (2010) cultural dimension of masculinity has been linked to undertaking activities for the purpose of self-promotion, and word of mouth (Lam, Lee, \& Mizerski 2009), and cultural dimension on indulgence vs. restraint to how important enjoyment is when undertaking different activities (Hofstede 2010). Thus, both dimensions can prove relevant when studying user responses to firm-generated content. We might also need to consider the joint effect of cultural dimensions on user responses rather than analysing individualism in isolation.

In conclusion, while cross-cultural literature increases our understanding of the differences in online behaviour across countries, existing studies are mainly descriptive (focusing on the crosscountry comparisons without addressing the question of why the differences exist.) Moreover, their context is limited in terms of analysed behaviours and studies that do take cultural dimensions into account arrive at contradictory results regarding the influence of specific cultural dimensions on user online behaviour. Thus, to establish a deeper understanding of dissimilarities in online behaviours this paper takes into account cultural dimensions of in-group collectivism, or masculinity, and indulgence versus restraint from established cultural frameworks of Hofstede (2010) and House et al. (2004).

\subsection{Cultural dimensions used in the study}

\subsubsection{In-group Collectivism}

In-group collectivism relates to the notion of interdependence and is defined by House et al. (2010: 118) as "The degree to which organizational and societal institutional practices 
encourage and reward the collective distribution of resources and collective action”. Thus, individuals from cultures scoring high on in-group collectivism tend to identify themselves with their families and have pride in their affiliations with others in their reference group, whereas cultures scoring low on this dimension identify with their reference groups to a lesser extent (House et al. 2010). We use in-group collectivism instead of Hofstede's individualism, as the latter combines two sub-dimensions: Institutional Collectivism and In-group Collectivism (House, Quigley \& de Luque 2010). In-group collectivism is more relevant in the context of our study, as on Facebook responses to firm-generated content take place in the context of interactions with users' friends (their reference group). In-group collectivism is related to user motives such as social integration and personal identity (self-presentation, self-expression). These motivations are group-referent and can only be fulfilled through social interactions with users’ online friends (Eisenbeiss et al. 2012; Dholakia, Bagozzi and Pearo 2004).

\subsubsection{Masculinity}

As argued in the literature review section, the results from prior studies on the role of collectivism in encouraging user responses are contradictory. To understand the origin of these contradictory findings, we study the joint effect of cultural dimensions on user responses rather than analysing individualism in isolation. We argue that the dimension of masculinity vs.

femininity is relevant in the context of public responses to firm-generated content. Masculinity as a cultural dimension is related to the notion of competitiveness, self-interest, and power (House et al. 2004; Peabody 1985; Schein 1992; Fyans et al. 1983; Laurant 1986). "Masculinity stands for a society in which social gender roles are clearly distinct. Men are supposed to be assertive, tough, and focused on material success; women are supposed to be more modest, tender, and concerned with the quality of life. (...) Femininity stands for a society 
in which social gender roles overlap. Both men and women are supposed to be modest, tender, and concerned with the quality of life." (Hofstede et al. 2010: 297). Cultures with high scores on this dimension are referred to as masculine, and with low scores as feminine. Masculine cultures are task-oriented, admire material success and emphasize competition, assertiveness, and achievement, whereas feminine cultures are relationship-oriented, value caring for others, cooperation, and modesty. Unlike in masculine cultures, in feminine societies being boastful about one's accomplishments is frowned upon (Hofstede et al. 2010). Therefore, the cultural dimension of masculinity vs. femininity is related to social integration (especially helping), personal identity (including self-presentation, self-expression, and self-assurance), and remuneration (Lam, Lee and Mizerski 2009).

\subsubsection{Indulgence vs. Restraint}

Indulgence vs. restraint as a cultural dimension is related to the notion of obtaining gratification and enjoyment versus controlling human desires (Hofstede et al. 2010). "Indulgence stands for a tendency to allow relatively free gratification of basic and natural human drives related to enjoying life and having fun. Restraint reflects a conviction that such gratification needs to be curbed and regulated by strict social norms.” (Hofstede et al. 2010: 281). In cultures characterized by high levels of indulgence, leisure time, having fun and gratification of one’s desires are valued. On the other hand, high-restraint cultures control the satisfaction of their desires and value conforming to strict social norms regarding what is acceptable behaviour. Thus, in those cultures, leisure activities or expressing oneself are of little importance (Hofstede et al. 2010: 281). Therefore, the indulgence vs. restraint cultural dimension is highly relevant when theorizing the importance of entertainment motives and users perceived freedom to publicly respond to firm-generated content in social media. 


\section{Methodology}

\subsection{Sampling}

\subsubsection{Country choice}

There are three different groups of factors influencing social media usage i.e.: enabling technology (and technology adoption) (Srite \& Karhanna 2006; Steers, Meyer, \& SanchezRunde 2008), governmental policies, and sociocultural factors (Berthon et al. 2012). Therefore, to isolate the impact of cultural factors, the countries chosen for this study are similar regarding both technological levels and governmental regulations of social media. As previous research arrived at a consensus on the role of cultural dimensions of uncertainty avoidance and long-term orientation in online user behaviour, the countries we selected were to be at the same level on those dimensions (both with either a high or low score).

As the research has not arrived at a consensus regarding social media use in individualistic and collectivistic cultures, we deemed it necessary to study the role of this cultural dimension further. Thus, chosen countries had to represent cultures with low and high levels of in-group collectivism. To deepen this analysis and investigate the role of cultural dimensions that were previously neglected by the academic research, but which are promising to explain the differences in previous findings as argued above, chosen countries had to differ on masculinity and indulgence vs. restraint dimensions. Table 1. presents the scores of cultural dimensions for studied countries.

Table 1. Cultural dimensions of Finland and Poland*

\begin{tabular}{cccc}
\hline & $\begin{array}{c}\text { Masculinity } \\
\text { (Hofstede } \\
\text { 2001) }\end{array}$ & $\begin{array}{c}\text { Indulgence } \\
\text { vs. } \\
\text { Restraint } \\
\text { (Hofstede } \\
\text { 2001) }\end{array}$ & $\begin{array}{c}\text { In-group } \\
\text { Collectivism } \\
\text { (House et } \\
\text { al. 2004) }\end{array}$ \\
\hline Finland & 26 & $\mathbf{5 7}$ & 4.23 \\
\hline Poland & $\mathbf{6 4}$ & 29 & $\mathbf{5 . 5 5}$ \\
\hline
\end{tabular}


*in bold the values of cultural dimensions considered by Hofstede (2001) and House et al. (2004) as high, in italic as low.

Our analysis pertains to the cultural dimensions of indulgence vs. restraint, masculinity (Hofstede et al. 2010), and In-group Collectivism (House et al. 2004). Finland represents an individualistic, feminine, and indulgent culture, whereas Poland is a highly collectivistic, masculine culture characterized by Restraint.

\subsubsection{Study subjects}

Given the importance of taking context into account, we applied purposive (non-probability) sampling (Glaser \& Strauss 1967) and considered the following factors: sample equivalence, daily social media use, Internet proficiency, and cultural exposure.

Firstly, scholars suggest that in cross-cultural research, sample differences should be minimized so that other factors do not explain the results. This is achieved by selecting samples matching the primary characteristics (Van de Vijver and Leung 1997; Singh, Holzmueller and Nijssen 2006). Therefore, to achieve sample equivalence and draw more exact theoretical predictions, we looked for populations comparable across studied countries (Calder, Philips \& Tybout 1981). Secondly, Lynch (1999: 370) suggests that researchers should ask if the sample is typical on the constructs in question compared to "real people". We were looking for a considerably large segment of social media users. Therefore, we took into account that among the followers of firmgenerated content on Facebook, there are significantly more younger users than old ones (Lipsman, Mudd, Rich, \& Bruich 2012). We also considered the level of subjects’ Internet proficiency, their familiarity with, and frequency of social media use, and experiences with firmgenerated content. Thirdly, minimal intercultural exposure was also taken into account. Based on these criteria, subjects for this research were sampled from student populations in Finland and Poland. Students represent similar age groups, education levels, and experience with 
social media, and therefore are a relatively homogenous group. This homogeneity of sample reduces the error variance and results in a stronger test of theory (DuFrene, Engelland, Lehman, \& Pearson 2005). Furthermore, students are one of the largest groups of Facebook users (Mack, Behler, Roberts \& Rimland 2007). Thus, paraphrasing Lynch’s (1999) cited above question of whether the sample represents typical social media users, in our study, students constitute a large segment of "real social media users".

When selecting subjects for participation in the interviews, the sampling procedure was purposive. Interviewees were recruited via personal contacts and referrals from other informants (Patton 1990). For the interviews to validate the study findings beyond the younger generation sampled for participation in diary research, interviews were conducted among working professionals. Other criteria used for recruiting informants were: each consumer uses social media on a weekly basis and follows some firms on social media. The average age of the interview sample was 46 years old, 50\% were men. Table 2. presents the characteristics of the interviewees and information about interviews. 
Table 2. Interviewees

\begin{tabular}{|c|c|c|c|c|c|c|c|}
\hline No. & Nationality & $\begin{array}{c}\text { Age } \\
\text { (years) }\end{array}$ & Gender & $\begin{array}{l}\text { Length of } \\
\text { social } \\
\text { media use }\end{array}$ & $\begin{array}{l}\text { Social media } \\
\text { platforms } \\
\text { used }\end{array}$ & $\begin{array}{c}\text { Frequency of } \\
\text { social media } \\
\text { use }\end{array}$ & $\begin{array}{c}\text { Interview } \\
\text { length }\end{array}$ \\
\hline 1 & FI & 29 & female & 6 years & $\begin{array}{l}\text { Facebook } \\
\text { LinkedIn }\end{array}$ & $\begin{array}{l}3 \text { times/ } \\
\text { week: 1h/day }\end{array}$ & $1.5 \mathrm{~h}$ \\
\hline 2 & FI & 51 & male & 6 years & $\begin{array}{l}\text { Facebook } \\
\text { LinkedIn }\end{array}$ & 2-3h/day & $45 \mathrm{~min}$ \\
\hline 3 & FI & 55 & male & 5 years & $\begin{array}{l}\text { Facebook } \\
\text { LinkedIn } \\
\text { Twitter }\end{array}$ & 1-2h/day & $1.5 \mathrm{~h}$ \\
\hline 4 & FI & 43 & female & 10 years & $\begin{array}{l}\text { Facebook } \\
\text { LinkedIn }\end{array}$ & 1-2h/day & $1.5 \mathrm{~h}$ \\
\hline 5 & PL & 46 & female & 4 years & Facebook & 3h/day & $45 \mathrm{~min}$ \\
\hline 6 & PL & 28 & female & 5 years & $\begin{array}{l}\text { Facebook } \\
\text { LinkedIn }\end{array}$ & $0.5-1 \mathrm{~h} /$ day & $1.5 \mathrm{~h}$ \\
\hline 7 & PL & 54 & male & 7 years & $\begin{array}{l}\text { Facebook } \\
\text { LinkedIn } \\
\text { Twitter }\end{array}$ & 1 h/day & $1 \mathrm{~h}$ \\
\hline 8 & PL & 58 & male & 5 years & $\begin{array}{l}\text { Facebook } \\
\text { LinkedIn }\end{array}$ & 1.5-2h/day & $1.5 \mathrm{~h}$ \\
\hline
\end{tabular}

The interviews were tape-recorded and transcribed verbatim.

\subsection{Data collection}

According to Cognitive Response Theory, “the spontaneous thoughts (cognitive responses) elicited by exposure to a message act as direct mediators of attitude formation” and immediate reports of those spontaneous thoughts mirror cognitive reactions taking place during the exposure to the message (Olson, Toy, \& Dover 1982). Therefore, when choosing the method appropriate for this study, it was considered that it should enable respondents to express their spontaneous responses to the firm-generated content they are exposed to. Thus, data for this research was collected through research diaries, open-ended user narratives, and interviews. Figure 1 presents the data collection process. 


\begin{tabular}{|c|c|c|c|}
\hline SAMPLE & \multicolumn{2}{|c|}{$\begin{array}{l}\text { YOUNG SOCIAL MEDIA USERS } \\
\text { IN FINLAND AND POLAND }\end{array}$} & $\begin{array}{l}\text { WORKING PROFESSIONALS } \\
\text { IN FINLAND AND POLAND }\end{array}$ \\
\hline $\begin{array}{c}\text { SAMPLE } \\
\text { CHARACTERISTICS }\end{array}$ & $\begin{array}{c}32 \text { participants } \\
\text { Average age: } \\
44 \%(56) \text { men(women) }\end{array}$ & $\begin{array}{c}34 \text { participants } \\
\text { Average age: } \\
47 \%(53) \text { men(women) }\end{array}$ & $\begin{array}{c}8 \text { interviewees } \\
\text { Average age } 46 \text { years old } \\
50 / 50 \% \text { (men/women) }\end{array}$ \\
\hline $\begin{array}{l}\text { DATA COLLECTION } \\
\text { PROCEDURE }\end{array}$ & $\begin{array}{r}\text { (1) RESEA } \\
\text { Users keep a diar } \\
\text { firm-generated con } \\
\text { on F } \\
\text { Event- } \\
\text { Semi- } \\
\text { Self-ac } \\
\text { Durati } \\
\end{array}$ & $\begin{array}{l}\text { DIARIES } \\
\text { their responses to } \\
\text { hey are exposed to } \\
\text { ook } \\
\text { ingent } \\
\text { tured } \\
\text { istered } \\
7 \text { days }\end{array}$ & $\begin{array}{l}\text { (3)INTERVIEws } \\
\text { Comparison of users experiences with firm- } \\
\text { generated content reported by young social } \\
\text { media users, and older population of } \\
\text { working professionals. } \\
\text { Topics discussed: } \\
\text { Responses to firm-generated content in } \\
\text { social media. } \\
\text { Motivations to respond. } \\
\text { The role of social norms. } \\
\text { Design: } \\
\text { Semi-structured } \\
\text { Total duration: } 8.5 \text { hours }\end{array}$ \\
\hline COLLECTED DATA & 763 diary reports & 157 pages & 83 pages of transcribed material \\
\hline
\end{tabular}

Figure 1. Data collection process

Research diary is defined as "a research tool that requires respondents to make regular records of their daily lives and experiences” (Mariño, Minichiello, \& Browne 1991). For seven days, study subjects reported on their experiences of firm-generated content and elaborated on their responses to it.

With this event-contingent diary procedure, participants reported firm-generated content whenever they found themselves exposed to it (posts appeared on their Facebook timeline from Facebook pages they previously clicked 'like’; or suggested posts appeared on their timeline). Participants described the firm-generated content they were exposed to and elaborated on their responses to it (was firm-generated content shared, commented, clicked 'like', or only privately 
consumed, or ignored?). They also described underlying motives for their public and private responses to firm-generated content.

This study format incorporating event-contingent diaries allowed us to capture users' immediate responses and details of their experience with firm-generated content without retrospective bias (Wheeler \& Reis 1991) or interviewer effect (Iida, Shrout, Laurenceau, \& Bolger 2012), and without exposure to firm-generated content being removed from its social context. This procedure assured the ecological validity of the study (Bolger, Davis, \& Rafaeli 2003) and allowed us to provide an accurate account of informants’ social media experiences, including their motivations to privately or publicly respond to firm-generated content. In total, 66 individuals participated in the diary study: 32 Finnish, 34 Polish (See Table 1). They were students from universities in Finland and Poland. They were offered extra credits for participation in the study. They reported their responses to 763 firm-generated posts. Each of the participants reported on average 12 instances of firm-generated content, with the number of reports ranging from a total of just 3 up to 47. Thus, the sample was diverse and included individuals with a different intensity of social media participation.

Table 3. Diary reports

\begin{tabular}{cccc}
\hline Country & Finland & Poland & Aggregated \\
\hline No. of respondents & 32 & 34 & 66 \\
\hline $\begin{array}{c}\text { No. of diary reports } \\
\text { Av. no. of reports per } \\
\text { participant }\end{array}$ & 437 & 326 & 763 \\
\hline$\%$ male (female) & 14 & 10 & 12 \\
\hline
\end{tabular}

In the second phase of the study, diary participants were asked to write open-ended narratives on the role of social media in their daily lives, their expectations regarding firm-generated content, and how and why they had typically responded to firm-generated content over the past seven 
days of diary keeping. Aside from revealing the underlying motives of participants' responses, open-ended narratives situated their replies within the context of user motivations and exposed the social norms of behaviour (Moisander \& Valtonen 2006) allowing us to explore how those norms restrict public responses to firm-generated content in a particular cultural context. In addition, we conducted eight interviews with users who did not participate in the diary exercise. They represented a different demographic group (see section 3.1.2. for more details), and thus the interviews served to validate the study findings beyond the younger generation (represented in the diary research) by sampling diverse group of working professionals.

\subsection{Data analysis}

The data was analysed through qualitative data analysis (Glaser \& Strauss 1967; Corbin \& Strauss 1990; Spiggle 1994). The objectives of this study addressed the scarcity of the theoretical knowledge on user responses to firm-generated content and the study aimed at theory development. Thus, data analysis was guided by a systematic combining approach. Systematic combining allows us to merge deductive and inductive thinking by moving back and forth between our data set and existing literature (Dubois and Gadde 2002) rather than strictly following a priori theoretical framework or conducting analysis without any framework in mind (Piekkari, Plakoyiannaki, \& Welch 2010). This process was carried out in six stages, during which the textual data was read nine times. The process was supported by NVivo software. In the first step, we conducted open-coding (Corbin and Strauss 1990). The pages of written text were dissected, sentence by sentence, with the purpose of identification of preliminary categories. This process consisted of recognizing the concepts emerging from the textual data, and categorizing user responses to firm-generated content and their underlying motives (Sinkovics et al. 2008). Any responses to firm-generated content and their underlying motives 
were coded with an in vivo descriptor (e.g. 'I shared it because my friends will appreciate me letting them know about this event.', or 'I shared it with friends because my friends respect me for sharing this type of post).

In the second step, to reduce the in vivo descriptors to codes (Corbin and Strauss 1990), we classified in vivo descriptors into concepts, which represented the context of different motivations to respond to firm-generated content (e.g., the in vivo descriptor 'I shared it with friends because my friends respect me for sharing this type of posts' was categorized as 'gaining recognition for sharing content').

Third, those initial categories were related to each other through axial coding (Corbin and Strauss 1990). The axial coding involved identifying concepts that can be grouped together. To ensure the internal consistency and discreteness of the categories, we asked two questions (Jarzabkowski 2008): (1) Is this code similar to the other code? (2) Is this code different from the other code? This step resulted in forming categories (e.g., gaining recognition). While grouping the concepts into the categories, we were moving back and forth between inductive thinking, the existing body of knowledge and deductive thinking to recognize and incorporate any emerging themes (Sobh and Perry 2006) including motivations for online behaviour identified by existing literature. As a result of this process the following codes emerged: (I) Responses to firmgenerated content: (1) ignored, (2) private response (watching or reading the content), (3) public responses (including content sharing, clicking ‘like’, commenting, or tagging; (II) Motivations to respond to firm-generated content (1) maximizing personal utility, (2) individuation, (3) selfenhancement, (4) expressing care/helping others, (5) gaining information-based power, (6) selfindulgence. 
Next, to verify the quality of the coding framework, a method corresponding to that used by other qualitative researchers (Dutton, Ashford, Neill \& Lawrence 2001; Jarzabkowski 2008) was used. A researcher familiar with the research objectives of the study and informed of the coding framework (Miles and Huberman, 1994), as well as fluent in both languages provided a check of the corresponding author's coding. She followed the procedure for ensuring the internal consistency and discreteness of the categories (outlined above). Her comments were favourable and supported that the text represents an accurate insight into user responses to firm-generated content in both countries, and she also pointed to the instances where, in her opinion, the data did not fit the specified coding framework. Initial reliability ratings between her and the corresponding author's codings (Miles and Huberman 1994) were above $94 \%$ for each of the codes, and the disagreements were resolved through discussion.

The next phase involved between-country comparison, aiming at the identification of the commonalities and differences in how users respond to firm-generated content in Finland and Poland.

Furthermore, we checked whether there were any differences in data collected from different samples: from diaries and narratives (sample of young social media users), and from interviews (sample of working professionals). In what follows we present the study findings. Supporting quotes are presented in Tables 4-7.

\section{Findings}

\subsection{The role of social media in subjects' everyday lives}

Among our study subjects in both countries, the key motivation for social media use is first and foremost keeping in touch with their online friends (social integration), and second, access to information related to hobbies and news (see Table 4. Row 1 for the supporting quotes). These 
motivations are consistent with previous research on the motives for social media participation (Dholakia et al. 2004; Eisenbeiss, Blechschmidt, Backhaus \& Freund 2012; Heinonen 2011; Seidman 2013; Gironda and Korgaonkar 2014). The frequency of reported social media use is similar in both countries - the majority of users access social media daily or several times a day regardless of the country of origin. The usual responses to firm-generated content are experiencing content privately (e.g. content watching or reading), or publicly clicking 'like’ and sharing firm posts. 
TABLE 4: Representative quotes of the informants' motivations

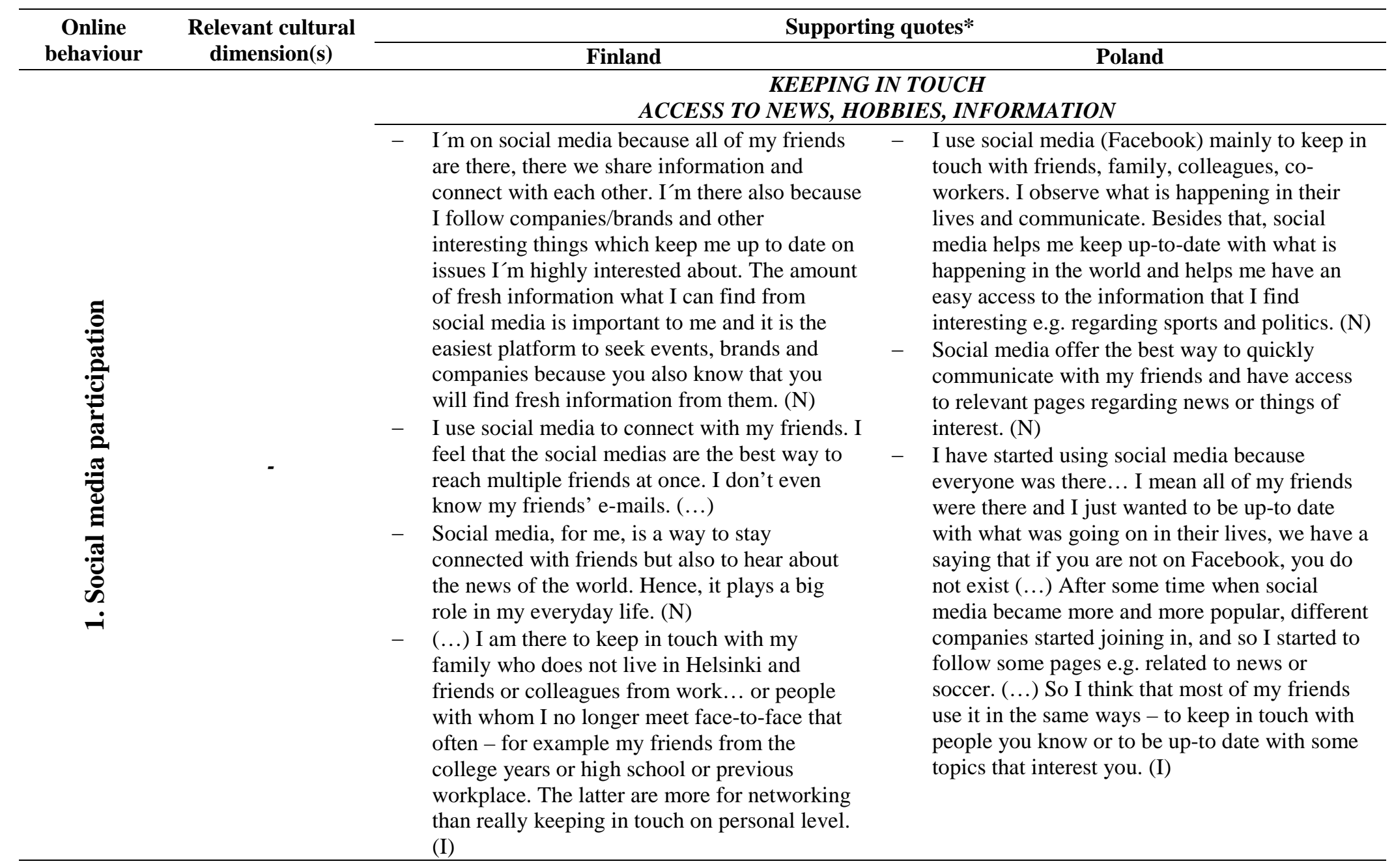

*(D) - quotation from respondent diaries; (N) -quotation from open-ended narrative; (I) -interview quote. 


\subsection{In-group Collectivism and engagement in social media}

On average, Finnish respondents were exposed to 14 firm posts during the diary-keeping period (posts appeared on their Facebook timeline from Facebook pages they previously clicked 'like', or suggested posts appeared on their timeline), whereas Polish respondents were exposed to 10 firm-generated posts. While studied countries are similar on how often users use social media in their daily lives, Polish informants respond to firm-generated content publicly (by sharing, tagging, commenting, or clicking 'like') almost four times more often than Finish informants. Moreover, responses of Finns involve mainly privately reading or watching content. (See Table 5. for the frequencies of private versus public responses to firm-generated content reported in user diaries).

Table 5. Reported responses to firm-generated content

\begin{tabular}{|c|c|c|}
\hline \multirow{2}{*}{ ENGAGEMENT BEHAVIOURS } & \multicolumn{2}{|c|}{ COUNTRY } \\
\hline & FINLAND & Poland \\
\hline \% OF PUBLIC RESPONSES ${ }^{1}$ & $8 \%$ & $31 \%$ \\
\hline$\%$ CLICKING LIKE ${ }^{2}$ & $84 \%$ & $89 \%$ \\
\hline$\%$ SHARING $^{2}$ & $19 \%$ & $20 \%$ \\
\hline$\%$ COMMENTING $^{2}$ & $3 \%$ & $14 \%$ \\
\hline$\%$ TAGGING $^{2}$ & $3 \%$ & $7 \%$ \\
\hline \% OF PRIVATE RESPONSES & $49 \%$ & $40 \%$ \\
\hline \% OF CONTENT IGNORED & $43 \%$ & $29 \%$ \\
\hline
\end{tabular}

Notes:

${ }^{1}$ Read as the percentage of diaries that reported public responses to firm-generated content in the total number of firm-generated content reported by subjects in a particular country

${ }^{2}$ Read as the proportion of this type of response to firm-generated content in all public responses reported by subjects in a given country; the percentages of different public responses do not sum up to $100 \%$ as one can click 'like', comment on, share or tag the same firm-generated content. 
Finnish subjects are less likely than Polish ones to respond publicly to firm-generated content (click 'like,' comment, share, or tag the firm-generated content). They prefer to privately read and watch content on their own, rather than publicly respond to it, even though motivations to use social media are the same in both countries. Moreover, Finnish subjects are more likely than Polish subjects to ignore firm-generated content (43\% of reported firm-generated content in Finland was ignored versus $29 \%$ in Poland). Thus, a question arises as to why those differences between countries exist, and in what manner culture influences users' willingness to publicly respond to firm-generated content they are exposed to.

As previously discussed, there has been a discussion in the literature regarding how collectivism influences the intensity of social media use (Goodrich and De Mooij 2014; Okazaki and Taylor 2013; Yang et al. 2011).

The diary reports of Finnish and Polish subjects in this study show that in-group collectivism influences the response type (private vs. public response to firm-generated content) rather than the intensity of social media use. (See Table 6. for supporting quotes). Our study suggests that user responses to firm-generated content in individualistic cultures are more private, whereas collectivistic cultures publicly respond to firm-generated content by disclosing their preferences to their online connections through content sharing or engaging in conversations through commenting on firm-generated content. Our subjects in Finland (an individualistic country) ask 'What is in it for me? - How is this content relevant to what I am doing right now?' before publicly responding to firm-generated content, whereas in Poland (a collectivistic country) users publicly respond to content with the intention of keeping in touch with their online friends. 
TABLE 6: Representative quotes of the informants' motivations

\begin{tabular}{|c|c|c|c|c|}
\hline \multirow{2}{*}{$\begin{array}{c}\text { Online } \\
\text { behaviour }\end{array}$} & \multirow{2}{*}{$\begin{array}{l}\text { Relevant cultural } \\
\text { dimension(s) }\end{array}$} & \multicolumn{3}{|c|}{ Supporting quotes* } \\
\hline & & Finland & & Poland \\
\hline \multirow[b]{2}{*}{ 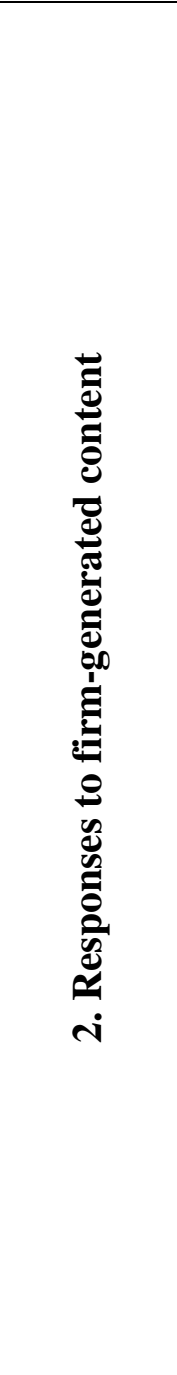 } & & $\begin{array}{c}\text { FOCUS ON THE LEISURE ACTIVITY, MAXIMIZING } \\
\text { PERSONAL UTILITY } \\
\text { - Is this content related to the leisure activity I am } \\
\text { pursuing? } \\
\text { PRIVATE RESPONSES }\end{array}$ & & $\begin{array}{l}\text { FOCUS ON KEEPING IN TOUCH WITH FRIENDS } \\
\text { - Is this content helping me connect with my } \\
\text { friends? } \\
\text { PUBLIC RESPONSES }\end{array}$ \\
\hline & $\begin{array}{l}\text { I COLLECTIVISM } \\
\text { FINLAND: LOW } \\
\text { POLAND: HIGH }\end{array}$ & $\begin{array}{l}\text { - I would not spend time on something that is } \\
\text { not somehow related to my interests or my life } \\
\text { (N). } \\
\text { I have no idea why some products are being } \\
\text { advertised to me (...), it can be frustrating to } \\
\text { read about some personally absolutely } \\
\text { meaningless Canaries vacation. (N) } \\
\text { _ I mostly read the posts that I find of special } \\
\text { importance. I get relevant information related } \\
\text { to my hobbies such as music or yoga. It has to } \\
\text { be something of high personal interest for me } \\
\text { to like it and take my time to read at all. If it } \\
\text { has no information that I find relevant I simply } \\
\text { ignore it. (D) } \\
\text { My responses not only depend on the type of } \\
\text { content that shows up, but when it is shared. If } \\
\text { I am on social media because I am bored and I } \\
\text { am looking for some entertaining video that } \\
\text { my friends shared on Facebook, and I see some } \\
\text { irrelevant firm posts, my reaction will not be } \\
\text { positive, or if I logged in with the intention to } \\
\text { read some articles on Salsa... I subscribe to } \\
\text { some pages on Salsa dancing (...) and I am } \\
\text { disturbed by some ad, I will also not be happy } \\
\text { about it, but when I was looking for a necklace } \\
\text { to buy, I did respond positively to this kind of } \\
\text { posts. (...) So... it all depends on the context } \\
\text { and why I am there at the time and what I am } \\
\text { doing at the time. (I) }\end{array}$ & $\begin{array}{l}- \\
- \\
- \\
-\end{array}$ & $\begin{array}{l}\text { The content that I share with others was such } \\
\text { that was somehow relevant to my friends' } \\
\text { activity and commenting it would help to stay in } \\
\text { touch (N). } \\
\text { I went to their Facebook page immediately } \\
\text { when I saw that my friend shared it (...) I } \\
\text { wanted to help him to (...) this is also a good } \\
\text { way for us to follow this up with a messenger } \\
\text { conversation and update each other on our lives } \\
\text { (D) } \\
\text { [Firm-generated content I share] helps me to } \\
\text { somehow connect with my friends, something } \\
\text { that I know they either find of interests, or } \\
\text { relates to something we have done together, and } \\
\text { in general some 'hot' topic that I know will } \\
\text { stimulate the discussion and my friends will be } \\
\text { commenting on. (I) }\end{array}$ \\
\hline
\end{tabular}




\subsection{Maximizing personal utility from the perspective of cultural dimensions of Collectivism}

and Masculinity

Goodrich and De Mooij (2014) suggest that low level of Collectivism contributes to using social media for maximizing personal utility and thus content searching, and Okazaki and Taylor (2013) suggest that it contributes to undertaking self-promotion activities through content sharing. In this study, Finnish subjects (representing low levels of Collectivism) as predicted by this previous research to maximize their utility. However, they do so not through content sharing as previously suggested (Goodrich \& De Mooij, 2014; Okazaki \& Taylor, 2013), but through private reading and watching of the content that they find relevant (See Table 6). They follow firm-generated content related to their hobbies and interests and privately respond to it through content reading and watching.

Standing out from the crowd (individuation) is frowned upon in feminine cultures (Hofstede 2010). As Finland is a feminine culture (with a low score of Masculinity (Hofstede et al. 2010)), sharing content for self-promotion would not be appreciated by users' online colleagues. Therefore, rather than sharing content that would enhance their image, Finns focus on whether sharing the content would hurt their image by making them appear boastful. Moreover, feminine cultures focus on caring for others (Hofstede et al. 2010). This behaviour is reflected in study subjects reporting that they consider whether firm-generated content helps them care for their online connections when deciding to publicly respond to the content (See Table 7.). Expressing care and helping others is reflected in sharing firm-generated content their friends find of value. Polish subjects, who engage in more public responses to firm-generated content than Finnish subjects, show more interest in standing out from the crowd by trying to enhance their image or celebrate their accomplishments through content sharing (See Table 7.). This behaviour is 
consistent with the fact that masculine cultures are driven by the need for achievement and constant improvement (Hofstede et al. 2010; McClelland, 1955, 1961).

Moreover, by sharing relevant content with others, users can obtain information-based power (Labrecque, vor dem Esche, Mathwick, Novak \& Hofacker 2013) based on how much they contributed to their community (p. 244; Baumeister 1998). Sharing relevant content with interested parties allows individuals to establish their position in the group and gain recognition (Labrecque et al. 2013), and Polish respondents share firm-generated content with this purpose in mind (See Table 7.).

Therefore, while informants in both countries publicly respond to firm-generated content by sharing content that helps and provides value to their connections, they do so with different underlying motivations. Finnish respondents share content to care for others, whereas Polish respondents publicly respond to firm-generated content to gain recognition in their social circle. 
TABLE 7: Representative quotes of the informants’ motivations

\begin{tabular}{|c|c|c|c|c|}
\hline \multirow{2}{*}{$\begin{array}{c}\text { Online } \\
\text { behaviour }\end{array}$} & \multirow{2}{*}{$\begin{array}{l}\text { Relevant cultural } \\
\text { dimension(s) }\end{array}$} & \multicolumn{3}{|c|}{ Supporting quotes* } \\
\hline & & & Finland & $\begin{array}{l}\text { Poland } \\
\end{array}$ \\
\hline \multirow{4}{*}{ 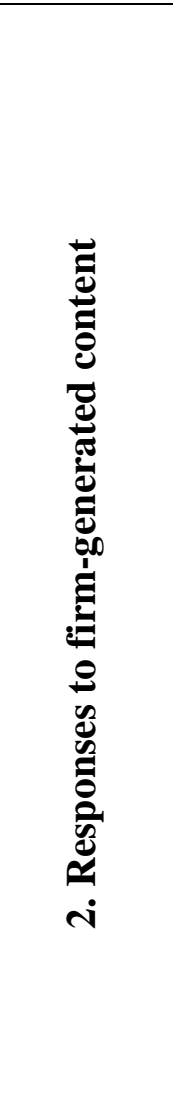 } & \multirow{4}{*}{$\begin{array}{l}\text { II MASCULINITY } \\
\text { FINLAND: FEMININE } \\
\text { POLAND: MASCULINE }\end{array}$} & & $\begin{array}{c}\text { RELATIONSHIP ORIENTATION } \\
\text { PROVIDING VALUE } \\
\text { PUBLIC RESPONSES }\end{array}$ & $\begin{array}{c}\text { SELF-PRESENTATION } \\
\text { FOCUS ON STANDING OUT, CELEBRATING } \\
\text { ACCOMPLISHMENTS } \\
\text { PUBLIC RESPONSES }\end{array}$ \\
\hline & & \multirow{3}{*}{\multicolumn{2}{|c|}{ 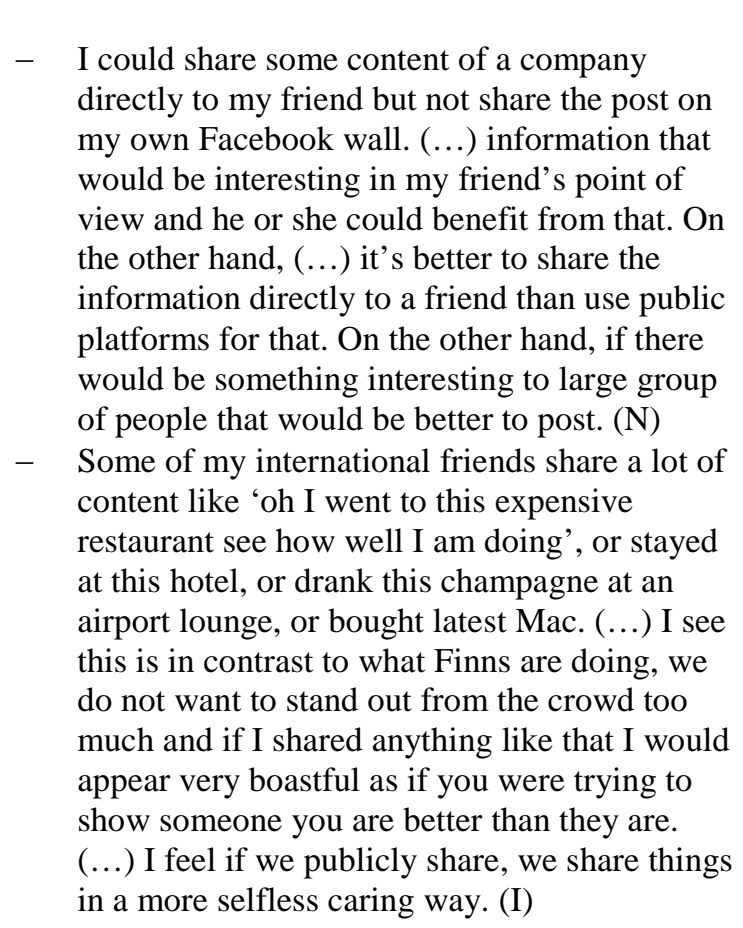 }} & $\begin{array}{l}\text { - } \text { In general, I tend to remain indifferent toward } \\
\text { company content on social media (...) I would } \\
\text { share the posts that help me enhance my image. } \\
\text { But nothing from any well-known brands as I do } \\
\text { not want to promote them for free. (N) } \\
\text { - I shared it because I wanted my friends to know } \\
\text { that I had the latest Mac. (D) } \\
\text { - I 'checked-in' the hotel so that my friends see } \\
\text { how well I am doing at my new job. (D) }\end{array}$ \\
\hline & & & & $\begin{array}{c}\text { NETWORK/INFORMATION POWER, RECOGNITION } \\
\text { PUBLIC RESPONSES }\end{array}$ \\
\hline & & & & $\begin{array}{l}\text { - If there is something that informs about big } \\
\text { sales - to share with friends to remind about } \\
\text { myself and be popular for giving useful content. } \\
\text { (N). } \\
\text { - I hardly share anything from companies unless it } \\
\text { is something on the discount etc. My friends } \\
\text { appreciate it. (N) } \\
\text { - I tagged the information on the gym that I know } \\
\text { my friend would appreciate. (D) }\end{array}$ \\
\hline
\end{tabular}

*(D) - quotation from respondent diaries; (N) -quotation from open-ended narrative; (I) -interview quote. 


\subsection{How indulgence versus restraint shape responses to firm-generated content}

According to existing research, users often become frustrated with irrelevant firm-generated content communicated to them on social media as it interferes with the ongoing activity they are performing at the time of the content exposure (Retie, 2001; Stone, 2010, AdReaction, 2010). However, as our study shows, the extent of negative reactions might be shaped by users' cultural background. This cultural influence is reflected in Finnish and Polish subjects responding differently to the firm-generated content intruding on their ongoing activities.

Individuals from societies characterized by indulgence feel free to act on their impulses and fulfil their desires regarding having fun and enjoying themselves. Leisure time in countries characterized by high Indulgence is appreciated and plays a major role in people’s lives. On the other hand, Restraint societies feel limited by social norms, and perceive self-indulgence as wrong, thus paying attention to controlling their yearnings (Hofstede et al.2010).

As reflected in supportive quotes (Table 8), Finnish subjects react very negatively when the content they are exposed to is imposed on them and does not fit the context of the leisure activity they perform. Relatedness to the ongoing activity concerns both the content itself and timing. As shown in previous sections, users respond to firm-generated content with a purpose in mind. Therefore, firm-generated content which is aggressive and/or communicated repeatedly results in a negative perception of the firm, especially when it is unrelated to and disturbs an ongoing leisure activity. Finnish subjects expect firms in social media to target them with content that fits into the context of what they are doing on social media at the moment when firm-generated content is communicated to them.

On the other hand, Polish subjects are not angered by firm-generated content that is unrelated to what they do and simply ignore it. They also tend to ignore a smaller proportion of firm- 
generated content and tend to be understanding of firms trying to present their content to them (See Table 8.).

Moreover, the fear of appearing indulgent, which was not revealed among Finnish subjects, prevents users in Poland from sharing some of the content. This happens in two different contexts: when they are exposed to firm-generated content at a time when they do not want their friends to see that they are 'wasting their time on Facebook' by publicly responding to it, or when the content relates to an activity or product that would make them appear indulgent. 
TABLE 8: Representative quotes of the informants' motivations

\begin{tabular}{|c|c|c|c|c|}
\hline \multirow{2}{*}{$\begin{array}{c}\text { Online } \\
\text { behaviour }\end{array}$} & \multirow{2}{*}{$\begin{array}{c}\text { Relevant cultural } \\
\text { dimension(s) }\end{array}$} & \multicolumn{3}{|c|}{ Supporting quotes* } \\
\hline & & \multirow{2}{*}{\multicolumn{3}{|c|}{$\begin{array}{cc}\text { Finland } & \text { Poland } \\
\text { USER REACTIONS TO CONTENT INTERRUPTING SOCIAL MEDIA ACTIVITY }\end{array}$}} \\
\hline \multirow{5}{*}{ 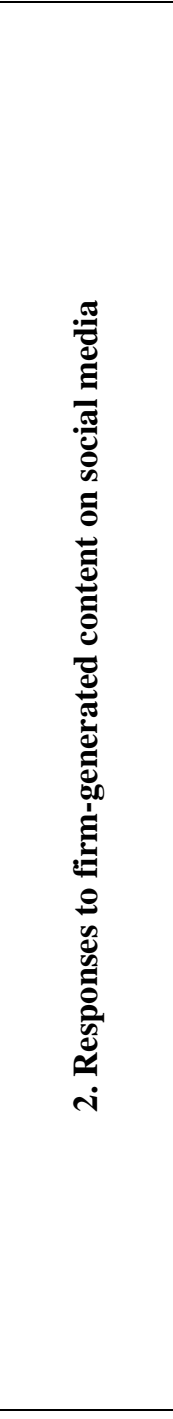 } & \multirow{5}{*}{$\begin{array}{l}\text { I INDULGENCE VS. } \\
\text { RESTRAINT } \\
\text { FINLAND: INDULGENT } \\
\text { POLAND: RESTRAINT }\end{array}$} & & & \\
\hline & & & BEING FRUSTRATED WITH CONTENT & IGNORING CONTENT \\
\hline & & & $\begin{array}{l}\text { You know what the users want. They want their } \\
\text { moment of peace. Why not construct your } \\
\text { marketing strategy around this idea instead of } \\
\text { thrusting more and more senseless messages } \\
\text { down their throats and hoping they won't start } \\
\text { banning your products for the remainder of their } \\
\text { lifetime? It's like an ex- partner who won't stop } \\
\text { sending you messages and calling you at } 2 \text { am, } \\
\text { even when you ask them not to. The only solution } \\
\text { is to block them, because they clearly are not } \\
\text { getting the message. (N) } \\
\text { My will, as a consumer is to watch a video about } \\
\text { cats. The company’s well calculated decision is to } \\
\text { interrupt that. My reaction will be hostile. (N) }\end{array}$ & $\begin{array}{l}\text { - I was reading the updates on the latest game, so this } \\
\text { company post was totally out of place for me as I am } \\
\text { not interested in buying a watch right now, so I ignored } \\
\text { it. (D) } \\
\text { _ } \quad \text { I understand companies want to market their products, } \\
\text { and have to use social media to try to reach us, but if I } \\
\text { am not interested I simply scroll down (N) } \\
\text { _ We all know that companies have to make their } \\
\text { money, and of course if I do not have to pay for using } \\
\text { Facebook, I understand that sometimes I will see some } \\
\text { company ads, but I think that is entirely } \\
\text { understandable. So I will just ignore this irrelevant } \\
\text { content, but no, it does not really affect my perception } \\
\text { of the company in any way (I) }\end{array}$ \\
\hline & & & $\begin{array}{l}\text { If I found the advert to interrupt me from doing } \\
\text { something that I was supposed to do for an }\end{array}$ & FEAR OF APPEARING INDULGENT \\
\hline & & & $\begin{array}{l}\text { extended period of time, I was irritated. (N) } \\
\text { When I share firm-generated content I want it to } \\
\text { somehow help my friends or perhaps not help but } \\
\text { at least be something they are interested in and a } \\
\text { piece of information they find valuable. Let's say } \\
\text { I know that my mother and few more friends like } \\
\text { knitting so yesterday when I saw a sweater... it } \\
\text { was from a fashion company, I shared it and } \\
\text { tagged them asking if they want to knit something } \\
\text { with this kind of pattern, because I thought they } \\
\text { might be interested in making one like that, it was } \\
\text { very beautiful. (I) }\end{array}$ & $\begin{array}{l}\text { - If I am not interested in what the company is posting I } \\
\text { will simply not share it, but also because I have many } \\
\text { different people as friends on Facebook, I will not share } \\
\text { something because I do not want them to know that I } \\
\text { am wasting my time on this game. (N) } \\
\text { - } \text { I did not share this content even though I am going to } \\
\text { buy it because I do not want my friends to think that I } \\
\text { am wasting my money on this while I should be saving. } \\
\text { (D) } \\
\text { I said I was supposed to be busy working at this time, } \\
\text { so if I share this, my friends will know that I am just } \\
\text { enjoying myself rather that going to that meeting. (D) } \\
\text { (...) For instance, sometimes there is a post I am very } \\
\text { interested in, and I would love to share it, but then I } \\
\text { stop myself because I do not want my friends to think I } \\
\text { am indulging in some idle gossips or parties, etc. (I) }\end{array}$ \\
\hline
\end{tabular}


*(D) - quotation from respondent diaries; (N) -quotation from open-ended narrative; (I) -interview quote. 


\section{Discussion}

This study contributes to social media behaviour literature by showing that not only what firms post, i.e., content design, but rather how their firm-generated content is aligned with user motivations, stemming from their cultural backgrounds, determines whether firm-generated content succeeds at stimulating desired user responses. While our understanding of user motivations for social media use has increased considerably over the past decade, previous studies in the field ignore that responses to firm-generated content and their underlying motivations vary depending on users’ cultural background.

Therefore, this qualitative paper is an answer to calls (Dahl, 2015; Okazaki \& Taylor, 2013;

Goodrich \& De Mooiji, 2014) to explore cultural influence on social media behaviour. Rather than focusing on descriptive comparisons between countries, we provide an answer as to why user responses to firm-generated content differ across cultures. We theorize how cultural dimensions of In-group Collectivism (House, Hanges, Javidan, Dorfman \& Gupta 2004), Indulgence vs. Restraint, and Masculinity (Hofstede, Hofstede \& Minkov 2010) explain differences in user motivations to respond to firm-generated content (See Figure 2.). Moreover, rather than looking at specific cultural dimensions in isolation, we establish the joint impact of in-group collectivism and masculinity on user responses to firm-generated content. We also demonstrate that, depending on user cultural background, social norms play less or more central influence on public responses to firm-generated content.

Figure 2. summarizes the user motives for responses to firm-generated content based on cultural background. While users in highly collectivistic cultures are motivated by keeping in touch with their online connections through public responses to firm-generated content, those in individualistic societies aim at maximizing their personal utility through privately consuming the 
content. People in masculine cultures publicly respond to firm-generated content to enhance their image and stand out from the crowd, whereas those from feminine cultures do not want to appear boastful by sharing self-enhancing content and publicly respond to content to express their care for others. While individuals in cultures characterized by a high Indulgence score focus on leisure activities, those in Restraint-classed societies are cautious of the content they publicly respond to for a fear of appearing indulgent.

\begin{tabular}{|c|c|c|c|c|c|c|}
\hline & \multicolumn{2}{|c|}{ COLLECTIVISM } & \multicolumn{2}{|c|}{ MASCULINITY } & \multicolumn{2}{|c|}{ INDULGENCE } \\
\hline & HIGH & Low & HIGH & Low & HIGH & Low \\
\hline $\begin{array}{l}\text { RESPONSES } \\
\text { TO FIRM- } \\
\text { GENERATED } \\
\text { CONTENT }\end{array}$ & $\begin{array}{c}\text { KEEPING IN } \\
\text { TOUCH }\end{array}$ & $\begin{array}{c}\text { MAXIMIZING } \\
\text { PERSONAL } \\
\text { UTILITY }\end{array}$ & $\begin{array}{c}\text { STANDING } \\
\text { OUT } \\
\text { SELF- } \\
\text { ENHANCEMENT }\end{array}$ & $\begin{array}{c}\text { CARING FOR } \\
\text { OTHERS } \\
\text { FEAR OF } \\
\text { APPEARING } \\
\text { BOASTFUL }\end{array}$ & $\begin{array}{l}\text { FOCUS ON } \\
\text { LEISURE } \\
\text { ACTIVITY }\end{array}$ & $\begin{array}{c}\text { FEAR OF } \\
\text { APPEARING } \\
\text { INDULGENT }\end{array}$ \\
\hline
\end{tabular}

Figure 2. Responses to firm-generated content - classification of user motives and fears based on cultural background

\subsection{Collectivism vs. Individualism}

Firstly, while previous studies did not arrive at a consensus whether collectivistic or individualistic cultures are more active on social media (Goodrich and De Mooij 2014; Okazaki and Taylor 2013; Yang et al. 2011), we show that it is not the intensity of social media use, but the type of user responses (public vs. private) to firm-generated content that differ among collectivistic and individualistic cultures. While collectivistic cultures engage more in public responses such as content commenting, tagging, or sharing, individualistic cultures focus on privately experiencing firm-generated content related to their interests with a focus on their leisure activities. Thus, we propose:

Proposition 1: In collectivistic cultures, users engage in more public responses to firm-generated content than in individualistic cultures. 
Proposition 2: In individualistic cultures users engage in more private responses to firmgenerated content than in collectivistic cultures

\subsection{The joint effect of Collectivism and Masculinity}

Secondly, another debate in existing literature pertained to the role of self-presentation motive in individualistic and collectivistic cultures. While previous research suggests that individualistic cultures use social media content for self-presentation and promotion (Goodrich and De Mooij, 2014; Okazaki and Taylor, 2013), our subjects from Finland (representing an individualistic country) are not driven by this kind of motivations. We are able to explain this contrasting finding by taking into account another cultural dimension i.e. masculinity (Hofstede’s et al. 2010). Our study shows that even users in a highly individualistic country might not engage in self-promotion activities when, at the same time, they represent a very feminine culture. Thus, we show that Okazaki and Taylor's (2013) claim might only be true for cultures that are both individualistic and masculine. Moreover, by integrating the concept of information-based power (Baumeister 1998; Labrecque et al. 2013), we show that users in collectivistic and simultaneously masculine cultures rather than individualistic cultures engage in self-oriented self-promotion activities. Under the pretence of contributing relevant content to their online connections, users from collectivistic and masculine cultures can try to establish their position in the group and gain recognition. Thus, we establish the relationship between masculinity and selfpromotion motives which was previously attributed only to the cultural dimension of individualism.

Therefore, we show that the cultural dimension of collectivism should not be interpreted in isolation. Even in countries characterized by low collectivism (high individualism), the importance of the motive for maximizing personal utility can be reduced by low levels of 
masculinity preventing users from acting in a self-enhancing manner and, resulting in users solely privately responding to firm-generated content. However, high levels of collectivism combined with high masculinity may result in content sharing with the aim of self-presentation. Thus, we also propose that:

Proposition 3: In collectivistic and masculine cultures, users publicly share firm-generated content to enhance their position within the group by sharing content relevant to their reference group.

Proposition 4: In individualistic and feminine cultures users avoid publicly sharing firmgenerated content to enhance their image, but share content that can help their reference group.

\subsection{Indulgence vs. Restraint}

Moreover, study findings suggest that previously neglected cultural dimension of indulgence vs. restraint (Hofstede et al. 2010) shape the extent to which users feel they have been disturbed by firm-generated content when it does not fit into an ongoing leisure activity. We propose that: Proposition 5: In indulgent cultures, firm-generated content that does not fit into an ongoing leisure activity meets with more negative responses than in restraint cultures. Moreover, by studying subjects' immediate responses to firm-generated content in the everyday context of online interactions that occur in their real lives, we reveal that the cultural dimension of indulgence vs. restraint influences the importance of social norms when publicly responding to firm-generated content. High levels of Restraint (low score of Indulgence) can make users less willing to publicly respond to firm-generated content through e.g. content sharing for the fear of appearing indulgent. Users in restraint cultures are either concerned that they will be perceived 
as people who waste their time on social media, or that the content they privately experience does not conform to social norms of their reference group. Thus, we propose:

Proposition 6: In restraint cultures, users avoid publicly responding to firm-generated content that does not conform to social norms in their reference group not to appear indulgent.

In sum, while previous research took into account the limited number of cultural dimensions of individualism, power distance, or uncertainty avoidance, our study shows that other cultural dimensions such as masculinity or indulgence vs. restraint play a vital role in shaping user responses to firm-generated content.

\section{Conclusions}

\subsection{Contributions}

Our study answers the call to study social media from a cross-cultural perspective (Dahl, 2015; Goodrich and De Mooiji 2014; Okazaki and Taylor 2013). The study provides a holistic perspective on user responses to firm-generated content by going beyond content characteristics, and situating these responses within the context of user social media experience. As a key contribution, by looking at both public and private responses to firm-generated content we demystify the idea that it is the intensity of social media participation that differs between individualistic and collectivistic cultures (e.g. Okazaki and Taylor 2013; Goodrich and De Mooiji 2014), and show that what differs is users' willingness to publicly respond to firmgenerated content. Most interestingly, our findings establish the role of the cultural dimensions

of masculinity, and indulgence versus restraint (Hofstede et al. 2010), which were not taken into account by previous research on social media behaviour. We also show that the role of cultural dimensions should not be analysed in isolation. By providing a more holistic perspective on the 
joint effects of cultural dimensions, and introducing the role of previously neglected dimensions, our findings help explain the contradictory findings in the scholarly works. Because we study user responses to firm-generated content in real life rather than them being removed from the context of their online connections and activities, we are able to look at how social norms shape user responses to firm-generated content in different ways. Ultimately, by integrating crosscultural theory into the analysis of user responses to firm-generated content, our results can help firms stimulate desired user responses to firms' social media content by helping them design content that addresses motives stemming from the cultural background of their target audience.

\subsection{Managerial implications}

Aside from theoretical contributions, the purpose of this paper is to help marketers develop firmgenerated content in social media that succeeds at stimulating desired user responses in different cultural markets. The study findings provide important guidance for international firms trying to develop firm-generated content that will be congruent with their target audience's cultural background and help companies decide whether to adapt or standardise their firm-generated content communicated on social media in different countries, based on the cultural background of their target groups.

We suggest that firms producing their content for markets in countries characterized by high indulgence pay close attention to their firm-generated content fitting ongoing leisure activities performed by the user at the time when the content is communicated to him or her. This finding suggests the importance of targeting content not only based on the demographic characteristics or interests of the user, but also the timing and ongoing social media activity of the user. On the other hand, users in societies characterized by restraint show more tolerance to content interrupting their activity, but are very conscious of not being judged based on the content they 
share. Thus, even if they enjoy the content and engage with it privately, they are reluctant to publicly respond to it, if their online friends do not approve of that particular issue. Thus, in restraint societies, marketers should pay attention to designing content that complies with commonly followed social norms. On the other hand, this shows that the firm-generated content that does not generate clicks on 'like' or shares in restraint cultures should not be automatically disregarded as unsuccessful at attracting user attention. Similarly, users in highly individualistic cultures try to maximize their personal utility by privately consuming the content and do not necessarily publicly share it. Thus, in individualistic cultures, in addition to relevant content, individual level incentives should be considered to encourage publicly sharing firm-generated content . When designing firm-generated content for masculine cultures, companies should keep in mind that if they want it to be publicly shared, it should help users enhance their image or enhance one's reputation among one’s reference group. On the other hand, content designed for feminine cultures should aid users in helping their connections if it is to be shared.

Thus, firms need to keep in mind that the potential toolbox required to stimulate sharing firmgenerated content publicly varies in culturally different markets. More important than content design is that it is it being targeted at user's interests and motivations stemming from their cultural background.

\subsection{Future research directions}

While our research addresses several critical gaps in the literature and establishes the importance of additional cultural dimensions, as well as analysing their joint impact when studying user responses to firm-generated content, we suggest promising future directions stemming from the limitations of this study. Although our findings establish the cross-cultural differences, the sampling frame impedes the generalization of the findings. Thus, we encourage future research 
to test our propositions on more diverse and bigger populations, as well as on a greater number of countries. Moreover, more countries should be studied to further establish the influence of other combinations of cultural dimensions.

While several studies on web commercials compared a student sample with a nonstudent sample and received mostly consistent results (the differences they found were attributable to web experience, i.e., students were more used to the Internet) (Stevenson, Bruner, \& Kumar 2000; Bruner \& Kumar 2000), and our interview findings were in line with the findings from diary research, we encourage future researchers to expand the sampling on older generations of social media users as they are becoming an important segment of social media users. Furthermore, as this study aimed at the exploration of the phenomena, future quantitative research is recommended to compare the importance of cultural dimensions and personal traits, or other demographic characteristics, on user responses to firm-generated content.

\section{References}

AdReaction (2010). Brands + Consumers + Social Media: What Marketers Should Know About Who’s Getting Social and Why. Dynamic Logic, January 26, 2010.

Berthon, P. R., Pitt, L. F., Plangger, K. \& Shapiro, D. (2012). Marketing meets Web 2.0, social media, and creative consumers: Implications for international marketing strategy. Business Horizons, 55:3, 261-271.

Bolger, N., Davis, A. \& Rafaeli E. (2003). Diary Methods: Capturing Life as it is lived. Annual Review of Psychology, 54, 579-616.

Bruner, G.C. and Kumar, A. (2000). Web commercials and advertising hierarchy-of-effects, Journal of Advertising Research, January/April, 35- 42. 
Calder, B. J., Philips, L. W., Tybout, A.M. (1981). Designing Research for Application. Journal of Consumer Research, 8, 197-207.

Chapman C.N., \& Lahav, M. (2008). International ethnographic observation of social networking sites. In CHI '08 Extended Abstracts on Human Factors in Computing Systems (CHI EA '08). ACM, New York, NY, USA, 3123-3128.

Choi, Y.K., Hwang, J S., McMillan, S.J. (2008). Gearing up for mobile advertising: A crosscultural examination of key factors that drive mobile messages home to consumers. Psychology \& Marketing, 25:8, 756-768.

Corbin, J. Strauss, A. (1990). Grounded Theory Research: Procedures, Canons, and Evaluative Criteria. Qualitative Sociology, 13(1), 3-21.

Christodoulides, G., Michaelidou, N. \& Argyriou, E. (2012). Cross-national Differences in EWOM Influence. European Journal of Marketing, 46:11-12, 1689 -1707. Online Adolescents. Journal of Computer-Mediated Communication,15, 109-137.

Dahl, S. (2015). Social Media Marketing:Theories and Applications, Sage: London.

De Vries, L., Peluso, A., Romani, S., Leeflang, P. \& Marcati, Al. (2017). Explaining consumer brand-related activities on social media: An investigation of the different roles of selfexpression and socializing motivations. Computer in Human Behaviour, 272-282.

Dholakia, U. M., Bagozzi, R. P., \& Pearo, L. K. (2004). A social influence model of consumer participation in network- and small-group-based virtual communities. International Journal of Research in Marketing, 21:3, 241-263.

Dubois, A. \& Gadde, L.E. (2002). Systematic combining: an abductive approach to case research. Journal of Business Research, 55, 553-600. 
DuFrene, D. D., Engelland, B. T., Lehman, C. M., \& Pearson, R. A. (2005). Changes in consumer attitudes resulting from participation in permission e-mail campaign. Journal of Current Issues and Research in Advertising. 27:1, 65-77.

Dutton, J., Ashford, S., O’Neill, R., \& Lawrence, K. (2001). Moves that matter: Issue selling and organizational change. Academy of Management Journal, 44, 716-736.

Eisenbeiss, M., Blechschmidt, B., Backhaus, K., \& Freund, P. A. (2012). The (real) world is not enough: Motivational drivers and user behavior in virtual worlds. Journal of Interactive Marketing, 26 :1, 4-20.

Forbes (2015) http://www.forbes.com/sites/kathleenchaykowski/2015/12/08/facebook-businesspages-climb-to-50-million-with-new-messaging-tools/\#3c9622c81c2c

Geertz, C. (1973). The interpretation of cultures. London: Fontana.

Gironda J. T., Korgaonkar, P. K. (2014). Understanding consumers’ social networking site usage. Journal of Marketing Management, 30(5-6), 571-605.

Glaser, B. G.; Strauss, A.L. (1967). The Discovery of Grounded Theory. Strategies for Qualitative Research. New York: Aldine.

Goodrich, K. \& de Mooij, M. (2014). How ‘social’ are social media? A cross-cultural comparison of online and offline purchase decision influences. Journal of Marketing Communications, 20:1/2, $1-14$

Heinonen, K. (2011). Consumer activity in social media: Managerial approaches to consumers' social media behavior. Journal of Consumer Behaviour 10. 356-364

Hofstede, G. (2001). Culture’s Consequences: Comparing Values, Behaviors, Institutions, and Organizations Across Nations, Second Edition. Thousand Oaks: Sage Publications, Inc. 
Hofstede, G., Hofstede, G.J. \& Minkov, M. (2010). Cultures and Organizations Software of the Mind: Intercultural Cooperation and Its Importance for Survival. New York: The McGrawHill Companies.

House R.J., Hanges P.J., Javidan M., Dorfman, P.W. and Gupta, V. (2004). Culture, Leadership, and Organizations: the GLOBE Study of 62 Societies, Thousand Oaks, CA: Sage

House, R. J., Quigley, N. R. \& De Luque, M. S. (2010). Insights from Project GLOBE. International Journal of Advertising 29:1, 111-139.

Iida, M., Shrout, P. E., Laurenceau, J. P., Bolger, N. (2012). Using diary methods in psychological research. In Cooper, H. (Ed.). APA Handbook of Research Methods in Psychology Foundations, Measures, and Psychometrics, 1, 277-305.

Jiacheng, W., Lu, L., \& Francesco, C. A. (2010). A cognitive model of intra-organizational knowledge-sharing motivations in the view of cross-culture. International Journal Of Information Management, 30(3), 220-230.

Jarzabkowski, P. (2008). Shaping Strategy as a Structuation Process. Academy of Management

Kumar, A., Bezawada, R., Rishika, R., Janakiraman, R., \& Kannan, P.K. (2016). From Social to Sale: The effects of firm-generated content in social media on customer behavior. Journal of Marketing, 80 (1), 621-650.

Labrecque, L. I., vor dem Esche, J., Mathwick, C., Novak, T., \& Hofacker, C. F. (2013). Consumer power: Eution in the Digital Age. Journal of Interactive Marketing, 27, 257-269.

Lam, D., Lee, A. \& Mizerski, R. (2009). The Effects of Cultural Values in Word-of-Mouth Communication. Journal of International Marketing, 17:3, 55-70.

Lee, D., Hosanagar, K., Nair, H.S. (2016). Advertising Content and Consumer Engagement on Social Media: Evidence from Facebook. XXX 
Leung, K., Bhagat, R.S., Buchan, N.R., Erez, M. \& Gibson, C.B. (2005). Culture and international business: recent advances and their implications for future research, Journal of International Business Studies, 36(4), 357-378.

Lipsman, A., G. Mudd, M. Rich, and S. Bruich. (2012). The Power of Like How Brands Reach (and Influence) Fans through Social-Media Marketing.” Journal of Advertising Research, $52: 1,40-52$.

Lynch Jr., J.G. (1999). Theory and external validity. The Journal of Academy of Marketing Science, 27:3, 367-376.

Mack, D., A. Behler, B. Roberts, and E. Rimland. (2007). Reaching Students with Facebook: Data and Best Practices. Electronic Journal of Academic and Special Librarianship.

Makri, K. \& Schlegelmilch, B. (2017). Time orientation and engagement with social networking sites: A cross-cultural study in Austria, China \& Uruguay. Journal of Business Research., http://dx.dot.org/10.1016/j.jbusres.2017.05.016.

Mariño, R., Minichiello V.\& Browne, J. (1991). Reporting of events using diaries. In: Minichiello, V., Sullivan, G., Greenwood, K., Axford, R. (eds). Handbook for research in health sciences. Sydney, Australia: Addison-Wesley.

Markus, H.R. \& Kitayama, S. (1991). Culture and The Self: Implications for Cognition, Emotion and Motivation, Psychological Review, 98:2, 224-253.

McClelland, David C., Studies in Motivation, Appleton-Century-Crofts, Inc., New York, 1955.

McClelland, David C., The Achieving Society, The Free Press, New York, 1961

Miles, M., \& Huberman, A. 1994. An expanded sourcebook: Qualitative data analysis. London: Sage. 
Moisander, J. \& Valtonen, A. (2006). Qualitative marketing research. A Cultural Approach. London, Thousand Oaks \& New Delhi: Sage.

Mosteller, J. \& Poddar, A, (2017). To Share and Protect: Using Regulatory Focus Theory to Examine the Privacy Paradox of Consumers' Social Media Engagement and Online Privacy Protection Behaviours. Journal of Interactive Marketing, 39:February, 27-38.

Muntinga, D., Moorman, M. \& Smit, E. (2011). Introducing COBRAs. International Journal of Advertising, 30:1, 13-46.

Nelson-Field, K, and Taylor, J. (2012). Facebook fans: A fan for life?, Admap, Assessed from http://www.warc.com/Content/ContentViewer.aspx?ID=b44fad20-c6f7-4d44-aac2da9ea7cf8383\&MasterContentRef=b44fad20-c6f7-4d44-aac2da9ea7cf8383\&Campaign=admap_may12\&utm_campaign=admap_may12

Nisbett R.E., Peng, K., Choi I., Peng K. \& Norenzayan A. (2001). Culture and Systems of Thought: Holistic Versus Analytic Cognition. Psychological Review, 108:2, 291-310.

Okazaki, S.\& Mueller, B. (2007). Cross-cultural advertising research: where we have been and where we need to go. International Marketing Review, 24(5), 499-518.

Okazaki, S. \& Taylor, C.R. (2013). Social media and international advertising: theoretical challenges and future directions. International Marketing Review, 30:1, 56-71.

Olson, J. C., Toy, D. R., \& Dover, P. A. (1982). Do Cognitive Responses Mediate the Effects of Advertising Content on Cognitive Structure?. Journal of Consumer Research, 9:3, 245262.

Pagani, M. Hofacker, C.F., Goldsmith, R.E. (2011). The influence of personality on active and passive use of social networking sites, 28:5, 441-456. 
Park C. Jun J., Lee T. (2015). Consumer characteristics and the use of social networking sites. International Marketing Review, 32:3/4, 414 - 437.

Patton, M. Q. (1990). Qualitative evaluation and research methods. Newbury Park, CA: Sage Publications.

Phua, J. \& Ahn, S.J. (2016). Explicating the "like” on Facebook brand pages: The effect of intensity of Facebook use, number of overall "likes" and number of friends' "likes" on consumers’ brand outcomes. Journal of Marketing Communications, 22:5, 544-559.

Piekkari, R., Plakoyiannaki, E., \& Welch, C.( 2010). 'Good’case research in industrial marketing: Insights from research practice. Industrial Marketing Management. 39:1, 109-117.

Pornpitakpan, C. (2004). Factors Associated with Opinion Seeking: A Cross-National Study. Journal Of Global Marketing, 17:2/3, 91-113.

Qiu, L., Lin, H. \& Leung, A. K.-y. (2013). Cultural Differences and Switching of In-group Sharing Behavior between an American (Facebook) and a Chinese (Renren) Social Networking Site. Journal of Cross-Cultural Psychology, 44:1, 106-121

Rokeach, M. (1973). The nature of human values, New York, Free Press.

Retie, R. (2001). An Exploration of Flow During Internet Use. Internet Research: Electronic Networking Applications and Policy, 11(2), 103-113.

Saridakis, C., Baltas, G., Oghazi, P. \& Hultman, M. (2016). Motivation recipes for brand-related social media use: A boolea -fsQCA approach. Psychology \& Marketing, 33:12, 10621070.

Shao, G. (2009). Understanding the appeal of user-generated media: a uses and gratification perspective. Internet Research, 19:1, 7-25.

Srite, M.\& Karahanna.E (2006).The Role of Espoused National Cultural Values in Technology Acceptance. MIS Quarterly, 30(3), 679-704. 
Steers, R., Meyer, A.\& Sanchez-Runde, C. (2008) National culture and the adoption of new technologies. Journal of World Business, 43(3), 255-260.

Seidman, G. (2013). Self-presentation and belonging on Facebook: How personality influences social media use and motivations. Personality and Individual Differences, 54, 402-407.

Shavitt, S., Lee, A.Y.\& Johnson, T.P. (2008). Cross-cultural consumer psychology. In. Haugtvedt, C., Herr, P. \& Kardes, F. (Editors). Handbook of Consumer Psychology. Mahwah, NJ: Lawrence Erlbaum, 1103-1131.

Shin, D.H. (2010).Analysis of online social networks: a cross-national study. Online Information Review.. 34 3,473-495.

SI (2016) http://www.smartinsights.com/social-media-marketing/social-media-strategy/newglobal-social-media-research/

Sibai, O., de Valck, K., Farrell, A. M., \& Rudd, J. M. (2015). Social Control in Online Communities of Consumption: A Framework for Community Management. Psychology \& Marketing, 32:3, 250-264.

Singh, J., Holzmueller H., and E. Nijssen (2006). Four Decades of Cross-Cultural Research Practices in International Marketing An Assessment and Advancement of Conceptual, Theoretical, Methodological and Analytical Issues. Academy of Marketing Science, Seoul Korea, 12-15 July.

Sinkovics, R. R., Penz, E. \& Ghauri, P. N (2008). Enhancing the Trustworthiness of Qualitative Research in International Business. Management International Review, 48:6, 689-713 Sloane, G. (2015). As Ad Blocker Usage Explodes, Can YouTube Win Back Scofflaws With a Subscription Model?. Adweek, 1. Retrived from 
http://www.adweek.com/news/technology/how-ad-blocking-could-affect-youtubessubscription-model-163983.

Sobh, R \& Perry, C. (2006). Research design and data analysis in realism research. European Journal of Marketing, 40:11/12, 1194-1209.

Spiggle, S. (1994). Analysis and Interpretation of Qualitative Data in Consumer Research.Journal of Consumer Research, 194-203.

Statista (2017) http://www.statista.com/statistics/272014/global-social-networks-ranked-bynumber-of-users/

Steinmann, S., Mau, G., \& Schramm-Klein, H. (2015). Brand communication success in online consumption communities: An experimental analysis of the effects of communication style and brand pictorial representation. Psychology \& Marketing, 32, 356-371

Stephen, A. T., Sciandra, M. R., \& Inman J.J. (2015). Is it what you say or how you say it? How content characteristics affect consumer engagement with brands on Facebook. Said Business School Research Papers, University of Oxford, 19, 1-58.

Stevenson, J. S., Bruner II, G. C., \& Kumar, A. (2000). Webpage Background and Viewer Attitudes. Journal Of Advertising Research. 40:1/2, 29-34.

Stokburger-Sauer, \& N.E., Wiertz, C. (2015). Online Consumption Communities: An Introduction. Psychology and Marketing, 32:3, 235-239.

Stone, B. (2010). Ads Posted on Facebook Strike Some as Off-Key. New York Times, March 4 (2010), B1, Retrieved from http://www.nytimes.com/2010/03/04/technology/04facebook.html?_r=0.

Strauss, A. \& Corbin, J. (1998). Basics of Qualitative Research - Techniques and Procedures for Developing Grounded Teory. Thousand Oak, CA: Sage. 
Taras, V., Kirkman, B. L. \& Steel, P. (2010). Examining the impact of Culture's consequences: A three-decade, multilevel, meta-analytic review of Hofstede's cultural value dimensions. Journal of Applied Psychology, 95:3, 405-X.

Taylor, D. G., Lewin, J.E., \& Strutton, D. (2011). Friends, Fans and Followers: Do Ads Work on Social Networks? How Gender and Age Shape Receptivity. Journal of Advertising Research, 51(1), 258-275.

Tsai, W.-H. \& Men, L.R. (2017). Consumer engagement with brands on social networking sites: a cross-cultural comparison of China and the USA. Journal of Marketing Communications, 23:1, 2-21.

Van de Vijver, F.J.R., Leung, K., 1997. Methods and data analysis of comparative research. second ed. In: Berry, J.W., Poortinga, Y.H., Pandey, J. (Eds.), Handbook of Cross-cultural Psychology, 1. Allyn \& Bacon, Boston, 257-300.

Van de Vijver, F., \& Poortinga, Y. H., (1997) Towards an Integrated Analysis of Bias in CrossCultural Assessment, European Journal of Psychological Assessment, 13:1, 21-29.

Van Doorn, J., Lemon, K.E., Mittal, V., Naß, S., Pick, D., Pirner, P., Verhoef, P.C. (2010). Customer Engagement Behavior: Theoretical Foundations and Research Directions, Journal of Service Research, 13, 253-266.

Vasalou A., Joinson A. N. \& Courvoisier D. (2010). Cultural differences, experience with social networks and the nature of true commitment in Facebook. International Journal of HumanComputer Studies, 68:10, 719-728.

Wheeler, L. \& Reis, H. T. (1991). Self-recording of everyday life events: origins, types, and uses. Journal of Personality, 59: 3, 339-54. 
Yadav, M. S., \& Pavlou, P. A. (2014). Marketing in Computer-Mediated Environments: Research Synthesis and New Directions. Journal of Marketing, 78:1, 20-40.

Yang J., Morris M.R., Teevan J., Adamic L.A. \& Ackerman M.S. (2011). Culture Matters: A Survey Study of Social Q\&A Behavior. Proceedings of the Fifth International AAAI Conference on Weblogs and Social Media, 409-41. 
